Original Article

\title{
Physical activity among working age residents of Wroclaw in the light of their educational attainment
}

\author{
Daniel Puciato ${ }^{1)}$ \\ 1) Faculty of Physical Education and Physiotherapy, Opole University of Technology: 76 Prószkowska \\ St., 45-758 Opole, Poland
}

\begin{abstract}
Purpose] This article attempts to define the relationship between physical activity and educational attainment of working-age adults from Wroclaw. [Subjects and Methods] The study surveyed 2,174 participants aged 18-64 years, 984 men and 1,190 women. To evaluate their physical activity, the International Physical Activity Questionnaire was used. [Results] Most of the participants performed low-intensity levels of physical activity. Men were characterized by generally higher physical activity than women, but the difference was not significant. The level of educational attainment differentiated physical activity only in women with secondary or higher education, who performed significantly more physical activities than those with primary and vocational education. [Conclusion] Further research in this subject area should be performed. It should be continuous and consider other methods and techniques.

Key words: Physical activity, IPAQ, Educational attainment
\end{abstract}

(This article was submitted Aug. 25, 2015, and was accepted Oct. 30, 2015)

\section{INTRODUCTION}

Physical activity has important to therapeutic effects, mainly preventive, and its absence increases the risk of lifestyle diseases, such as obesity, osteoporosis, diabetes type 2, ischemic heart disease, and certain types of cancers ${ }^{1,2)}$. Empirical studies indicate that approximately $30 \%$ of the adult population in Europe performs too little low-intensity physical activity ${ }^{3)}$. As a consequence, they run the risk of lifestyle diseases, which requires increased public spending for health protection. This is especially significant for working-age people, as in addition to medical expenses, the economic efficiency of enterprises decreases, and national finances are impacted due to increased pay-outs of sickness allowances from reduced tax revenues ${ }^{4}$.

The level of physical activity varies among different social groups, which can be grouped according to their educational attainment, and these relationships can be multidirectional. Some study results have shown that as the education level increases, the participation in various forms of physical activity also rises ${ }^{5}$. However, some reverse correlation, particularly with regard to male participants ${ }^{6}$.

This study attempted to define the relationship between physical activity and the educational attainment of working-age inhabitants of Wroclaw.

\section{SUBJECTS AND METHODS}

This study was conducted in November 2013 and involved 2,174 people aged 18-64, 984 males and 1,190 females. Respondents with basic and vocational education attainment comprised 30\% (383 males and 262 females) those with secondary education comprised 49\% (393 males and 676 females), while those with higher education comprised 21\% (208 males and

Corresponding author. Daniel Puciato (E-mail: d.puciato@po.opole.pl)

(C2016 The Society of Physical Therapy Science. Published by IPEC Inc.

This is an open-access article distributed under the terms of the Creative Commons Attribution Non-Commercial No Derivatives (by-nc-nd) License $<$ http://creativecommons.org/licenses/by-nc-nd/4.0/>. 
252 females) of the sample. The representative sample was randomly selected, and its age-gender structure was similar to the general population of Wroclaw (Poland).

For evaluation of physical activity the International Physical Activity Questionnaire — short version ${ }^{7}$ was used, which contains six questions on the physical activity of respondents in a typical week of their life. Activity covers physical efforts executed at work, home and in the surroundings, while moving from place to place, including the time after work.

Due to the lack of conformity between the analysed variables and the normal distribution, the following characteristics were computed: medians, quartile deviations, minimum and maximum values. The Mann-Whitney test for a sample of $\mathrm{n}>$ 20 and the Kruskal-Wallis test (ANOVA) were used. Statistical significance was accepted for $\mathrm{p}<0.05$. The calculations were carried out using IBM SPSS Statistics 20 software.

\section{RESULTS}

Tables 1 and 2 present the basic statistical characteristics of physical activity of the female and male participants, according to their educational attainment. It is worth noticing that in all groups, despite the level of educational attainment, male subjects dominated the category of physical activity with low intensity. Physical activity with medium and vigorous intensity undertaken less frequently by female and male respondents.

Males were characterized by generally higher physical activity than females. The observed differences were not statistically significant (Table 3).

Among the working-age subjects from Wroclaw, the level of education was not the biggest differentiating factor influenc-

Table 1. Physical activity of the males according to their educational attainment

\begin{tabular}{|c|c|c|c|c|c|}
\hline Variable & Education & $\mathrm{Me}$ & Q & Min & $\operatorname{Max}$ \\
\hline DVPA (min/week) & \multirow{3}{*}{ Basic and basic vocational } & 240.0 & 195.0 & 10.0 & 1260.0 \\
\hline DMPA (min/week) & & 240.0 & 150.0 & 40.0 & 1260.0 \\
\hline DTPA (min/week) & & 870.0 & 540.0 & 60.0 & 3780.0 \\
\hline DVPA (min/week) & \multirow{3}{*}{ Secondary } & 240.0 & 210.0 & 10.0 & 1260.0 \\
\hline DLPA (min/week) & & 420.0 & 410.0 & 30.0 & 1260.0 \\
\hline DTPA (min/week) & & 960.0 & 570.0 & 30.0 & 3780.0 \\
\hline DVPA (min/week) & \multirow{2}{*}{ Higher } & 240.0 & 190.0 & 10.0 & 1260.0 \\
\hline DMPA (min/week) & & 240.0 & 210.0 & 20.0 & 1260.0 \\
\hline
\end{tabular}

DVPA: weekly volume of physical activity with vigorous intensity, DMPA: weekly volume of physical activity with moderate intensity, DLPA: weekly volume of physical activity with low intensity, DTPA: weekly volume of physical activity

Table 2. Physical activity of the females according to their educational attainment

\begin{tabular}{lccccc}
\hline Variable & Education & Me & Q & Min & Max \\
\hline DVPA (min/week) & & 240.0 & 142.5 & 30.0 & 1080.0 \\
DMPA (min/week) & Basic and basic vocational & 180.0 & 120.0 & 10.0 & 1080.0 \\
DLPA (min/week) & & 360.0 & 375.0 & 20.0 & 1260.0 \\
DTPA (min/week) & & 775.0 & 550.0 & 80.0 & 2880.0 \\
DVPA (min/week) & & 240.0 & 180.0 & 10.0 & 1260.0 \\
DMPA (min/week) & Secondary & 240.0 & 210.0 & 10.0 & 1260.0 \\
DLPA (min/week) & & 420.0 & 337.5 & 10.0 & 1260.0 \\
DTPA (min/week) & & 907.5 & 525.0 & 40.0 & 3780.0 \\
DVPA (min/week) & & 240.0 & 180.0 & 10.0 & 1260.0 \\
DMPA (min/week) & Higher & 225.0 & 120.0 & 30.0 & 1260.0 \\
DLPA (min/week) & & 420.0 & 420.0 & 10.0 & 1260.0 \\
DTPA (min/week) & 937.5 & 575.0 & 50.0 & 3600.0 \\
\hline DVPA weekly vol. & & & &
\end{tabular}

DVPA: weekly volume of physical activity with vigorous intensity, DMPA: weekly volume of physical activity with moderate intensity, DLPA: weekly volume of physical activity with low intensity, DTPA: weekly volume of physical activity 
ing the volume of their physical activities. The exception was the female group with secondary educational attainment, which performed the largest volume of physical activity with moderate intensity, followed by the group of females with higher education, and the smallest volume of physical activity was performed by the group consisting of females with primary and vocational education. Similarly concerning total physical activity, the volume of physical activitiy being performed rose as the subjects' educational attainment increased. Both differences were statistically significant (Table 4).

\section{DISCUSSION}

Lack of physical activity is particularly hazardous for people of productive age, and due to this situation, the therapeutic function of physical activity, mainly in the form of prevention against lifestyle and occupational diseases, is insufficient. It also reduces the chances of high quality life in retirement ${ }^{8,9)}$.

In this study, no significant differences were found in the volumes of physical activity between female and male subjects. Whereas, findings made by other authors usually indicate higher levels of physical activity among men ${ }^{10)}$. This is probably related to lifestyle changes occurring in post-industrial societies, especially urban societies, mainly due to the progress of women's empowerment, flexibility of social roles, or the active leisure trends.

Despite the fact that there are many studies indicating that correlations exist between the level of educational attainment and the level of physical activity ${ }^{5,6,9)}$, in this study, this correlation was only found in the female group. This corresponds to some extent with the results obtained in another region of Poland ${ }^{6}$. The reason for this finding is probably that the male subjects generally had lower levels of education than the female subjects and the structure of the male group, according to the level of education being more uniform. In addition, men, especially those with lower educational attainment, are more likely to undertake physical activities at work ${ }^{5)}$, while those with higher levels of education are more like to perform physical activities in their leisure time ${ }^{6}$. This would lead to a situation in which the total physical activity performed by male subjects would be similar in volume, regardless of their education. This would further lead to the situation that the total physical activity performed by the male subjects would be similar in volume, regardless of their education. Higher volumes of physical activity performed in leisure time by people with higher levels of education was also found for female subjects. It is noteworthy that those with secondary education levels had increased awareness of the positive health impact of physical activity.

The study found statistically significant differences in the levels of physical activity of females with basic and vocational attainment and females with secondary and higher educational attainment, in favour of the last group. This referred only to physical activity of moderate intensity, and to total physical activity. This difference was not found among the male

Table 3. Differentiation of physical activities performed by adults with various educational attainment

\begin{tabular}{lccc}
\hline \multirow{2}{*}{ Variable } & $\begin{array}{c}\text { Basic and basic } \\
\text { vocational }\end{array}$ & Secondary & Higher \\
\cline { 2 - 4 } & $\mathrm{Z}$ & $\mathrm{Z}$ & $\mathrm{Z}$ \\
\hline DVPA (min/ week) & -1.41 & -0.31 & -0.35 \\
DMPA (min/ week) & -0.91 & -1.42 & -1.10 \\
DLPA (min/ week) & -0.76 & -1.16 & 0.35 \\
DTPA (min/ week) & -0.75 & -0.77 & -0.23 \\
\hline
\end{tabular}

DVPA: weekly volume of physical activitywith vigorous intensity, DMPA: weekly volume of physical activity with moderate intensity, DLPA: weekly volume of physical activity with low intensity, DTPA: weekly volume of physical activity

Table 4. Gender differentiation of physical activities performed by adults with various educational attainment

\begin{tabular}{lcc}
\hline \multirow{2}{*}{ Variable } & Females & Males \\
\cline { 2 - 3 } & $\mathrm{H}$ & $\mathrm{H}$ \\
\hline DVPA (min/week) & 0.94 & 0.96 \\
DMPA (min/week) & $5.56^{*}$ & 1.78 \\
DLPA (min/week) & 2.35 & 1.77 \\
DTPA (min/week) & $6.71^{*}$ & 0.47 \\
\hline
\end{tabular}

DVPA: weekly volume of physical activitywith vigorous intensity, DMPA: weekly volume of physical activity with moderate intensity, DLPA: weekly volume of physical activity with low intensity, DTPA: weekly volume of physical activity, ${ }^{*} \mathrm{p}<0.05$ 
participants. Further study of the relationships between physical activity and social and economic status should be performed. They should be continuous in nature and also take into account other physical activity research methods and techniques (for example the IPAQ Questionnaire in Long Form, pedometry and accelerometry).

\section{REFERENCES}

1) Murano I, Asakawa Y, Mizukami M, et al.: Factors increasing physical activity levels in diabetes mellitus: a survey of patients after an inpatient diabetes education program. J Phys Ther Sci, 2014, 26: 695-699. [Medline] [CrossRef]

2) Mynarski W, Cholewa J, Rozpara M, et al.: Recommendations for health-enhancing physical activities in type 2 diabetes patients. J Phys Ther Sci, 2015, 27: 2419-2422. [Medline] [CrossRef]

3) Sjöström M, Oja P, Hagströmer M, et al.: Health-enhancing physical activity across European Union countries: The Eurobarometer study. J Public Health, 2006, 14: 291-300. [CrossRef]

4) Puciato D, Mynarski W, Rozpara M, et al.: Motor development of children and adolescents aged 8-16 years in view of their somatic build and objective quality of life of their families. J Hum Kinet, 2011, 28: 45-53. [Medline] [CrossRef]

5) Schneider S, Becker S: Prevalence of physical activity among the working population and correlation with work-related factors: results from the first German National Health Survey. J Occup Health, 2005, 47: 414-423. [Medline] [CrossRef]

6) Puciato D, Rozpara M, Mynarski W, et al.: [Physical activity of adult residents of Katowice and selected determinants of their occupational status and socio-economic characteristics]. Med Pr, 2013, 64: 649-657. [Medline]

7) International Physical Activity Questionnaires: http://www.ipaq.ki.se/ipaq.htm (Accessed Aug. 10, 2015).

8) Ignasiak Z, Sławińska T, Dąbrowski A, et al.: The structure of physical activity in seniors from lower Silesia. Rocz Panstw Zakl Hig, 2013, 64: 67-73. [Medline]

9) Mynarski W, Rozpara M, Nawrocka A, et al.: Physical activity of middle-age adults aged 50-65 years in view of health recommendations. Eur Rev Aging Phys Act, 2014, 11: 141-147. [CrossRef]

10) Hirayama F, Lee AH, Binns CW: Physical activity of adults aged 55 to 75 years in Japan. J Phys Ther Sci, 2008, 20: 217-220. [CrossRef] 